\title{
Dinâmica do uso do solo como mecanismo para o desenvolvimento econômico do município de Cristalina (GO)
}

O município de Cristalina (GO) situa-se na mesorregião do Leste Goiano, estando a $281 \mathrm{~km}$ da capital, Goiânia, e se destaca nacionalmente pela representatividade econômica do setor agropecuário, fruto da consolidação do uso de técnicas de irrigação, com proeminência para o modelo tipo pivô central. Nesse sentido, realizouse uma pesquisa exploratória e descritiva objetivando a caracterização agroeconômica do município e a identificação dos respectivos agentes de transformação social e econômica. Posteriormente, partindo da hipótese de relação existente entre o fator determinante da quantidade ofertada, como influenciador da tomada de decisão acerca da alocação dos recursos água e terra, realizou-se uma pesquisa multimétodos, por meio de análises estatísticas, gráficas e diferenciais estruturais, aplicadas à dinâmica de mudança de uso do solo pelas principais culturas irrigadas por sistemas tipo pivot central. Verificou-se que o processo de expansão agrícola, que no município foi pautado na adoção de tecnologia de irrigação e diversificação de culturas, teve impacto direto na geração de renda e riqueza na economia do município; todavia, o setor de irrigação tem encontrado, devido à elevada demanda hídrica, restrições para expansão, o que pode vir a comprometer a trajetória de desenvolvimento econômico do município.

Palavras-chave: Tomada de decisão; Desenvolvimento sustentável; Irrigação.

\section{Land use dynamics as a mechanism for the economic development of the municipality of Cristalina (GO)}

The municipality of Cristalina (GO) is located in the East Goian mesoregion, being $281 \mathrm{~km}$ from the capital, Goiânia, and stands out nationally for the economic representativeness of the agricultural sector, as a result of the consolidation of the use of irrigation techniques, with prominence for the model. center pivot type. In this sense, an exploratory and descriptive research was carried out aiming at the agroeconomic characterization of the municipality and the identification of the respective agents of social and economic transformation. Subsequently, based on the hypothesis of a relationship between the determinant factor of the quantity offered, as an influencing decision making about the allocation of water and land resources, a multi-method research was carried out through statistical, graphica and structural differential analyzes applied. the dynamics of land use change by the main crops irrigated by central pivot systems. It was found that the agricultura expansion process, which was based on the adoption of irrigation technology and crop diversification, had a direct impact on the generation of income and wealth in the economy of the municipality; However, due to the high water demand, the irrigation sector has found restrictions on expansion, which may compromise the economic development trajectory of the municipality.

Keywords: Decision making; Sustainable development; Irrigation.

Topic: Desenvolvimento, Sustentabilidade e Meio Ambiente Reviewed anonymously in the process of blind peer
Received: 08/06/2019 Approved: 10/08/2019
Maria Gláucia Dourado Furquim (18)

Instituto Federal de Educação, Ciência e Tecnologia Goiano, Brasil http://lattes.cnpq.br/2681775689273863

http://orcid.org/0000-0001-7823-9546

maria.furquim@ifgoiano.edu.br

Klaus de Oliveira Abdala

Universidade Federal de Goiás, Brasil

http://lattes.cnpq.br/8041644148923970

http://orcid.org/0000-0002-6466-9905

agroklaus@gmail.com
Referencing this:

FURQUIM, M. G. D.; ABDALA, K. O.. Dinâmica do uso do solo como mecanismo para o desenvolvimento econômico do município de Cristalina (GO). Nature and Conservation, v.12, n.2, p.38-49, 2019. DOI: http://doi.org/10.6008/CBPC2318-2881.2019.001.0005 


\section{INTRODUÇÃO}

As inovações tecnológicas e organizacionais têm se apresentado como agentes de transformação do setor produtivo, elevando a competitividade dos atores econômicos e, por consequência, alterando a realidade local. No município de Cristalina, a interação entre inovação tecnológica em consonância com atributos de infraestruturas básicas como: disponibilidade hídrica, energia, comunicações, logística de transportes e telecomunicações dada a proximidade à capital federal, além de assessoramento financeiro por meio de acesso ao crédito que fomentou a ocupação de regiões do cerrado, foram fatores decisivos e diferenciadores para a promoção do desenvolvimento local.

Percebe-se que o município se apresenta na contramão, quanto à adoção de estratégias de desenvolvimento econômico, comumente pautada em processos vinculados à industrialização. Ao contrário, o processo de industrialização, terceirização e urbanização são consequências da consolidação do setor agropecuário, que atualmente figura entre os maiores PIBs do país. Aspecto igualmente importante, referese à coordenação dos diversos agentes sociais que atuam no território como sindicato rural, entidades de classe, centros de consultoria, instituições de ensino dentre outros.

Considerando a representatividade econômica dos empreendimentos rurais no município, a complexidade da tomada de decisão inerentes aos processos de planejamento e produção agrícola, demandam dos produtores rurais a análise de aspectos técnicos gerais que possibilite a redução das incertezas climáticas e de mercado, e por consequência proporcione maior retorno financeiro. Quando se trata da gestão de áreas agricultadas irrigadas, fatores adicionais condicionam a rentabilidade da atividade como: o uso da água, e sua característica de insumo e sua interrelação com o sistema composto por soloágua-planta-atmosfera (BORGES JÚNIOR, 2008).

Atualmente, Cristalina se destaca no país por possuir a maior área irrigada com sistema tipo pivô central e contribui para o abastecimento do mercado nacional não apenas de grãos mais também batata e cebola em $10 \%$ da produção do país, além de atomatados, milho semente e outras culturas que dependem de irrigação a decisão do produtor irrigante no que se refere ao que, quando, e quanto destinar de área para produção afetaria, por efeitos linkcage, toda a sócio economia da região.

Assim, pressupondo oferta, demanda e equilíbrio de mercado de um produto em específico e suas variações de preço de curto prazo, torna-se possível que agentes que estejam dentro do mercado e possuam informações privilegiadas lucrem com estes conhecimentos ao criarem mais que expectativas e sim oportunidades de mercado, adotando um modelo de decisão apoiado na teoria de expectativas racionais.

Diante do exposto, objetiva-se apresentar uma análise temporal, dos aspectos socioeconômicos que caracterizam o município de Cristalina (GO), constatando a intensificação do uso de equipamentos de irrigação do tipo pivô central, que por consequência favorece a estruturação de segmentos à jusante da produção, assim como identificar a dinâmica de uso de solo no sistema, que possa subsidiar a determinação das restrições de retração e expansão das áreas das culturas irrigadas, utilizando da hipótese de que a área 
cultivada respondia ao preço; sendo este cenário produtivo indicador para se planejar e fomentar o desenvolvimento local fruto da relação campo-cidade.

\section{Caracterização agroeconômica do município de Cristalina (GO)}

O município de Cristalina foi criado em 1916, após a Lei Estadual no 533, que elevou o Distrito de São Sebastião à emancipação, efetivada em janeiro de 1917 mediante pressão popular. Em 1918, por meio da Lei Estadual no 577, o nome de São Sebastião dos Cristais foi alterado para Cristalina, como permanece até os dias atuais. A extração e a comercialização de cristal de rocha, iniciadas pelos franceses Etiene Lepesqueur e Leon Laboissére, foi a principal atividade econômica desenvolvida até a década de 1970.

O cenário econômico da região, centrado na mineração e com atividades pastoris apenas de subsistência, começa a ser alterado a partir do final de 1950, inicialmente devido à construção de Brasília e, posteriormente, por ações governamentais destinadas a fomentar a ocupação e o desenvolvimento das regiões Norte e Centro-Oeste.

Dentre os programas governamentais de fomento, destacam-se o Segundo Plano Nacional de Desenvolvimento (II PND), destinado a promover a produção de insumos básicos e bens de capital, auxiliando no processo de modernização agrícola; o Programa Especial da Região Geoeconômica de Brasília (Pergeb), voltado a fomentar o desenvolvimento rural e agroindustrial e a promover a melhoria no abastecimento agrícola de Brasília, abrangendo 200 mil hectares de cerrado nos estados de Minas Gerais, Goiás, Bahia, Mato Grosso e Mato Grosso do Sul.

Além desses, citam-se o Programa de Cooperação Nipo-Brasileira para o Desenvolvimento dos Cerrados (Prodecer), idealizado em 1974, para estimular o desenvolvimento de uma agricultura moderna por meio da instituição de novos processos produtivos; e o Programa de Desenvolvimento dos Cerrados (Polocentro), desenvolvido no período de 1975 a 1979, com a finalidade de favorecer o desenvolvimento e a modernização agropecuária da região Centro-Oeste e do oeste do estado de Minas Gerais (ANA, 2013a; ANA, 2013b).

O uso de novas tecnologias, como a irrigação, se consolidou na região em virtude dos fatores naturais favoráveis, como as características de solo, clima, relevo e a abundância de recursos hídricos, uma vez que o município é banhado por 246 rios. Essa difusão tecnológica possibilitou crescentes aumentos de produção, primeiramente de grãos (feijão, milho, soja e outros). A expansão agrícola no município de Cristalina teve como marco os programas Prodecer e Polocentro, ao atrair e assentar agricultores especialmente das regiões Sul e Sudeste do País, sendo uma opção para produtores rurais de outras regiões do Brasil, com experiências produtivas agrícolas, que promovessem a ocupação racional do cerrado e seu aproveitamento em caráter empresarial. De acordo com Silva (2001), “[...] os recursos destinados ao POLOCENTRO abrangeram vários setores, tais como: armazenamento; energia; assistência; pesquisa e agropecuária; transporte e crédito rural, além de outras infraestruturas como: a eletrificação rural, mecanização e a utilização intensiva de corretivos do solo". 
A possibilidade de intensificação no uso dos recursos de produção fez com que o cultivo de algumas culturas se destacasse ao longo dos anos, com expressivo aumento em áreas plantadas por hectares, conforme apresentado na figura 1. Isso contribuiu para que as atividades agropecuárias desenvolvidas na região gradativamente adquirissem mais relevância econômica.

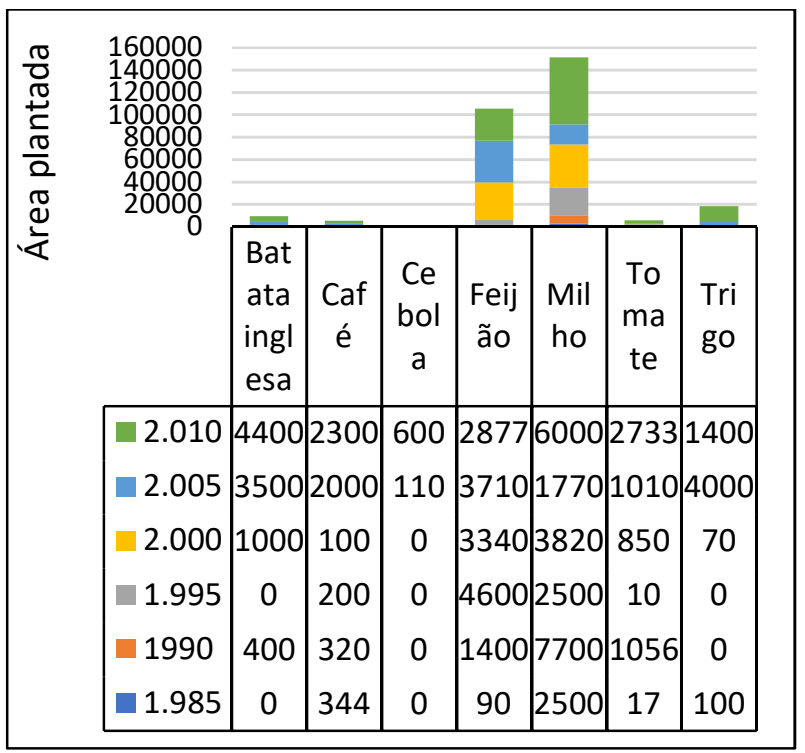

Figura 1: Culturas irrigadas em Cristalina (área plantada/hectares).

Esse processo de expansão agrícola e diversificação de culturas teve impacto direto na geração de renda e riqueza na economia do município. A participação do setor agropecuário foi crescente ao longo dos anos e, já no início do ano 2000, o valor do Produto Interno Bruto (PIB) agropecuário no município ultrapassa o valor adicionado bruto gerado pelo setor de serviços, consolidando sua importância como base da economia local (figura 2).

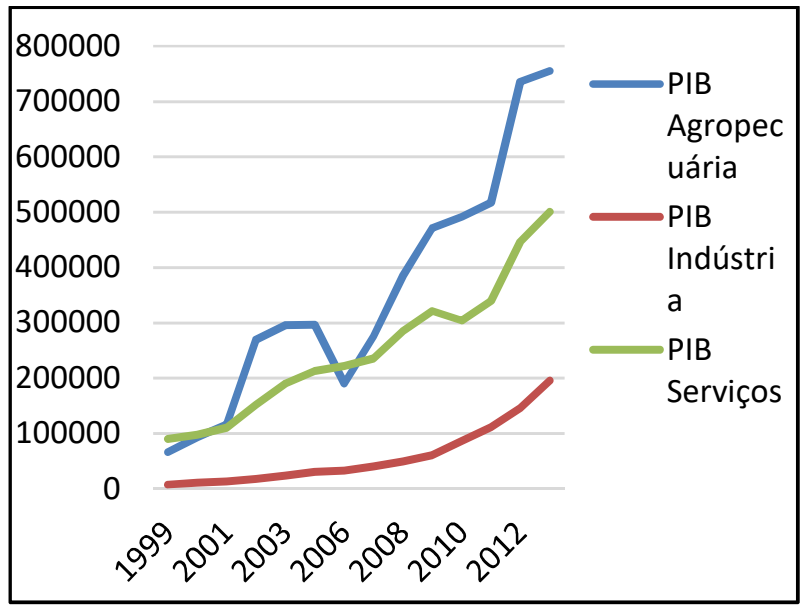

Figura 2: Evolução histórica do PIB de Cristalina (GO) (1999-2013). Fonte: IBGE (2016).

Em 2013, o município de Cristalina consolida também sua importância na produção de alimentos no país e, especialmente, na economia goiana, alcançando a posição de terceiro maior PIB agropecuário do estado e estando entre os maiores PIB agropecuários do Brasil. Além disso, sua configuração setorial se tornou diferenciada das configurações do estado de Goiás e do País, destacando a maior participação do setor agropecuário em relação aos demais. 
O município, constituído por uma área de $616.000 \mathrm{ha}$, possui configuração agrícola produtiva composta por 2.942 agricultores, sendo 147 produtores irrigantes e 2.795 assentados, pequenos e grandes produtores. Dentre as principais atividades agropecuárias desenvolvidas no município estão a agricultura de sequeiro, praticada em uma área de 259.200ha, que gerou, em 2015, um PIB de 1,1 bilhão de reais, e a agricultura irrigada, numa área de 56.370 ha, originando um PIB total de $R \$ 1.056 \mathrm{bi}$, dos quais, $R \$ 722 \mathrm{mi}$ são fruto do cultivo das culturas de alho, batata, cebola, cenoura, beterraba, batata-doce, tomate e ervilha, e $\mathrm{R} \$ 334 \mathrm{mi}$ advindos da produção de café, feijão, trigo, milho doce, milho verde e milho semente. Fazendo um comparativo entre o tipo de agricultura praticada no município (tabela 1), a área irrigada corresponde a 17,86\% do total da área agrícola e gera um PIB equivalente a $49 \%$ do valor apurado com a agricultura.

Tabela 1: Comparativo entre a agricultura de sequeiro e a irrigada para variáveis selecionadas no município de Cristalina (GO).

\begin{tabular}{|l|c|c|c|c|c|}
\hline \multicolumn{1}{|c|}{ Atividade agropecuária } & Uso do solo(ha) & Uso do solo (\%) & $\begin{array}{c}\text { PIB } \\
\text { (bilhões R\$) }\end{array}$ & $\begin{array}{c}\text { PIB } \\
\text { (\%) }\end{array}$ & $\begin{array}{c}\text { Geração de emprego } \\
\text { (pessoas ocupadas/ha) }\end{array}$ \\
\hline Agricultura de sequeiro & 259.200 & 82,14 & 1,1 & 51 & $1 / 100$ \\
\hline Agricultura irrigada & 56.370 & 17,86 & 1,0 & 49 & $1 / 9$ \\
\hline TOTAL & $\mathbf{3 1 5 . 5 7 0}$ & $\mathbf{1 0 0}$ & $\mathbf{2 , 1}$ & $\mathbf{1 0 0}$ & \\
\hline
\end{tabular}

Quanto à empregabilidade, a agricultura se destaca no município em comparação com os outros setores da economia, tendo aumentado significativamente o número de ocupação no setor, especialmente a partir de 2009. Uma das possíveis justificativas desse incremento decorre do benefício direto oriundo da adoção de sistema de irrigação, que gera empregos no campo, sendo em média uma pessoa contratada como mão-de-obra permanente a cada 9ha e uma pessoa contratada como mão-de-obra temporária a cada 6 ha. Enquanto isso, a empregabilidade na agricultura de sequeiro é de um emprego a cada 100ha plantados.

O município de Cristalina, em geral, têm se beneficiado dessa característica de polo de irrigação, que fomentou a constituição do polo agroindustrial, consolidado com a instalação de indústrias de beneficiamento e processamento de produtos alimentícios, como a Incotril, a Fugini, a Bonduelle e a Sorgatto, que, atraídas pela diversidade de culturas produzidas sob sistema de irrigação (especialmente a tipo pivô central), têm assegurado a disponibilidade de matéria-prima de boa qualidade durante praticamente o ano todo, até mesmo no período de entressafra.

Assim, o processo de crescimento econômico no município, está atrelado ao predomínio das atividades agrícolas na expansão da economia local, conforme refletido nos indicadores de quantidade do Produto Interno Bruto (PIB), ou seja, a soma de todos os bens e serviços produzidos durante certo período em um país, região ou município. Por sua vez, o desenvolvimento econômico contempla aspectos de cunho social, como taxa de analfabetismo, qualidade de vida, nível de consumo e acesso a saúde, ou seja, sinaliza a melhoria do bem-estar das pessoas e seu desenvolvimento humano.

De acordo com o Programa das Nações Unidas para o Desenvolvimento (PNUD) da Unesco, o Índice de Desenvolvimento Humano (IDH), “[...] considerar as numerosas dimensões do bem-estar humano, já que a atenção concentrar-se-ia assim sobre os fins para os quais o desenvolvimento deve servir, em vez de fazêlo apenas sobre os meios, por exemplo, para o aumento da produção" (UNESCO, 1999). 
Tendo por referência série histórica disponibilizada pelo IBGE (2017), que analisa o IDH do município e o compara com o estado, os resultados são respectivamente 0,699 e 0,735 (figura 3), ou seja, abaixo da média estadual e em faixa mediana de desenvolvimento humano, conforme critérios globais adaptados. Verificando aspectos relacionados a trabalho e rendimento conforme dados do IBGE (2017), verifica-se que o salário médio mensal dos trabalhadores formais é de 2,2 salários mínimos e 35,5\% da população apresenta rendimentos mensais de até meio salário mínimo por pessoa.

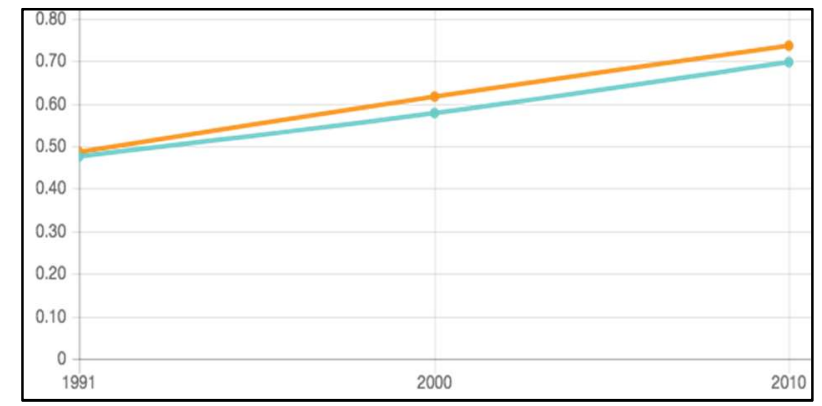

Figura 3: Série histórica do IDH de Cristalina em comparação ao Estado de Goiás (1991-2010).

Sobre o efetivo processo de desenvolvimento, Celso Furtado corrobora: 'O desenvolvimento não é apenas um processo de acumulação, de aumento de produtividade macroeconômica, mas principalmente o caminho de acesso às formas sociais mais aptas a estimular a criatividade humana e responder às aspirações da coletividade'. Esses indicadores preconizam a ideia de desenvolvimento numa concepção que não se restringe ao econômico, mas sim proporciona benefícios socioeconômicos em consonância com os anseios da coletividade.

Neste sentido, a renda (crescimento econômico) é uma forma de se alcançar melhorias na qualidade de vida, ou seja, um desdobramento do crescimento econômico, conforme contribui Veiga (2005) "[...] Maneiras viáveis de produzir meios de vida não podem depender de esforços excessivos e extenuantes por parte de seus produtores, de empregos mal remunerados exercidos em condições insalubres, da prestação inadequada de serviços públicos e de padrões subumanos de moradia".

\section{METODOLOGIA}

O município de Cristalina, em Goiás, situa-se na mesorregião do Leste Goiano e na microrregião do Entorno do Distrito Federal, estando a $281 \mathrm{~km}$ da capital Goiânia e tendo como municípios limítrofes: Ipameri (GO), Luziânia (GO), Paracatu (MG), Unaí (MG), Cidade Ocidental (GO) e Distrito Federal. Quanto às características naturais, possui vegetação e clima típicos da região dos cerrados, sendo as particularidades vegetais da região, formações florestais, savânicas e campestres; os atributos climáticos se dividem em duas estações distintas, sendo uma seca e frio que corresponde ao período outono-inverno, e a outra úmida e quente de verão. O município também é privilegiado em recursos hídricos, possuindo mais de 240 rios e nascentes (CARNEIRO et al., 2011). A figura 4 apresenta a delimitação territorial de Cristalina, suas bacias hidrográficas e a espacialização dos equipamentos de pivô central instalados no município. 


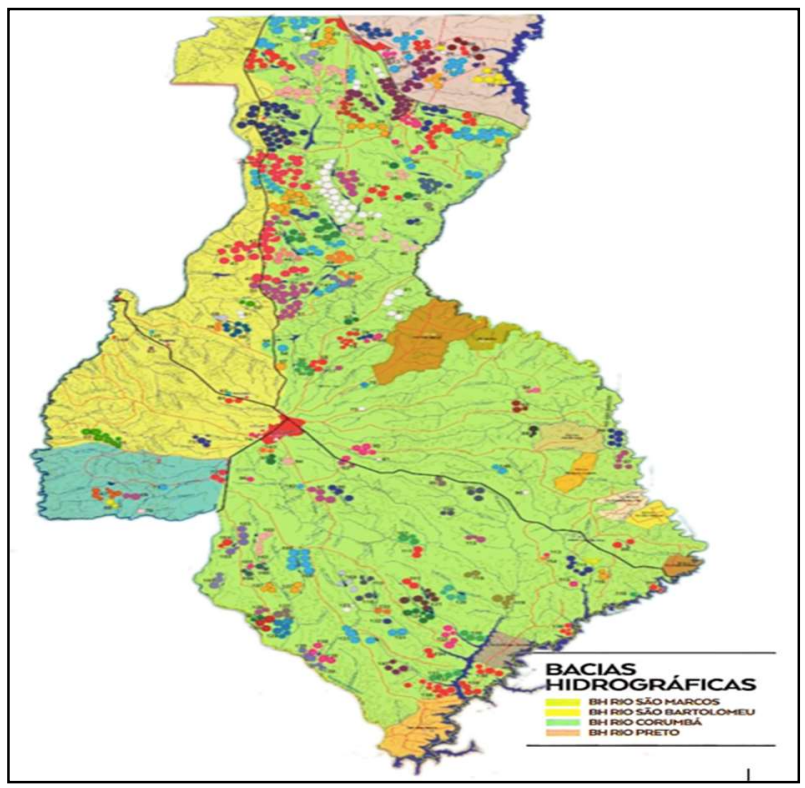

Figura 4: Delimitação territorial de Cristalina.

Para alcançar o objetivo proposto, adotou-se uma abordagem exploratória, por meio da análise de dados secundários, disponibilizados pelo Sindicato Rural e Prefeitura Municipal de Cristalina, IMB, Instituto Brasileiro de Geografia e Estatística (IBGE) e Agência Nacional das Águas (ANA). A análise temporal possibilitou apresentar os aspectos que impulsionaram o desenvolvimento e promoveram a transformação econômica do município em termos de políticas públicas e programas de governo.

Num segundo momento, para identificar a dinâmica do uso do solo em áreas irrigadas por pivô central, foi utilizado o método Shift-Share, conforme aplicado por: Pimentel (1998), Yokoyama et al. (1989) e Gomes (1998), que possibilita a análise do comportamento produtivo de determinado setor em determinado período de tempo, considerando de forma particularizada a realidade local acerca de aspectos específicos como expansão ou substituição de determinada atividade conforme período analisado.

Conforme contribui Simões (2005), "O método shift-share consiste, basicamente, na descrição do crescimento econômico de uma região nos termos de sua estrutura produtiva”. Segundo Santos (2009), "Este modelo permite decompor a alteração da área cultivada de um produto em relação a outro, em função da variação do tamanho do sistema [...] de produção (efeito escala), ou da substituição de um produto por outro, dentro do sistema (efeito-substituição)".

Assim, foram identificadas as principais culturas irrigadas produzidas na safra de inverno 2015 e suas respectivas áreas de cultivo, conforme apresentadas na tabela 2, sendo essas informações oriundas do Sindicato Rural de Cristalina para as culturas de milho, alho, batata-inglesa, cebola, feijão, milho doce e semente, tomate e trigo, sendo desconsideradas as culturas com menos expressividade em área cultivada no período analisado e cuja ausência de informações nos institutos de pesquisa inviabilizaram a inclusão no modelo, sendo elas: café, cenoura, beterraba, milho pamonha, aveia, batata-doce e frutíferas, que totalizam 5.750 hectares.

Para calcular a receita unitária(R) das diferentes culturas (tabela 3 ), foram coletados dados de valor da produção agrícola municipal, os quais foram divididos pela quantidade produzida no município, obtendo- 
se o preço unitário pago ao produtor, o qual foi multiplicado pela respectiva produtividade média, permitindo obter a receita unitária para cada cultura, de maneira a eliminar o efeito das oscilações de preço.

Tabela 2: Principais culturas irrigadas produzidas na safra de inverno/2015 em Cristalina (GO).

\begin{tabular}{|l|c|}
\hline \multicolumn{1}{|c|}{ Culturas } & Área plantada / há \\
\hline Alho & 1.800 \\
\hline Batata-inglesa & 4.000 \\
\hline Cebola & 2.220 \\
\hline Feijão (em grão) & 10.000 \\
\hline Milho doce & 12.000 \\
\hline Milho semente & 12.000 \\
\hline Tomate & 3.500 \\
\hline Trigo (em grão) & 5.000 \\
\hline \multicolumn{2}{c}{ Total } \\
\hline
\end{tabular}

Para a cultura de milho semente, foi utilizada a base de preços BM\&F BOVESPA menos $15 \%$ do valor, uma vez que esta é a referência adotada no pagamento ao produtor, conforme parâmetros contratuais estabelecidos junto às produtoras de semente de milho. Utilizaram-se, para tanto, dados do período de 2006 a 2015. Esses valores nominais foram deflacionados com a aplicação de um índice geral de preços, o IGP-DI, para obter os valores reais que serviram de parâmetro para o cálculo de média simples dos valores recebidos pelo produtor por $\mathrm{kg}$.

Quanto às informações do preço de venda e produtividade do milho doce, assim como os demais dados específicos do município, estes também foram obtidos junto ao Sindicato Rural de Cristalina e da Irrigo, sendo, portanto, dados primários que ilustram a realidade da agricultura irrigada no município. De acordo com Arenales (2011), “[...] a validação do modelo depende de a solução do modelo matemático ser coerente com o contexto original". Por sua vez, Ackoff (1979) informa sobre a necessidade de considerar os envolvidos no processo de decisão e aqueles que podem ser afetados por ele, ou seja, proporcionar uma melhor simplificação da realidade. Quanto à produtividade, foram utilizados valores decorrentes da média obtida com base no período analisado sendo empregados os dados disponíveis pelo IBGE.

Tabela 3: Informações de preço, produtividade e receita total para as atividades consideradas.

\begin{tabular}{|l|c|c|c|}
\hline \multicolumn{1}{|c|}{ Culturas } & $\begin{array}{c}\text { Preço de venda } \\
\text { (R\$//kg) }\end{array}$ & $\begin{array}{c}\text { Produtividade } \\
\text { (kg/ha) }\end{array}$ & $\begin{array}{c}\text { Receita unitária } \\
\text { (R\$/ha) }\end{array}$ \\
\hline Alho & 4,82 & 13205 & $63.689,13$ \\
\hline Batata-inglesa & 0,81 & 38200 & $31.043,68$ \\
\hline Cebola & 1,15 & 53778 & $62.151,30$ \\
\hline Feijão (em grão) & 2,30 & 2322 & $5.363,10$ \\
\hline Milho doce & 0,5 & 15000 & $7.500,00$ \\
\hline Milho semente & 0,46 & 5854 & $2.736,75$ \\
\hline Tomate & 0,38 & 85807 & $33.228,78$ \\
\hline Trigo (em grão) & 0,77 & 4818 & $3.749,35$ \\
\hline
\end{tabular}

\section{Resultados da dinâmica do uso do solo no município de Cristalina: indicadores de mecanismo de tomada de decisão em áreas irrigadas sob pivô central}

A água, quando utilizada artificialmente por meio de infraestrutura hídrica, consiste em matériaprima que compõe o sistema de produção agrícola, assim como sementes, máquinas e implementos, mãode-obra e agroquímicos. Neste sentido, de acordo com Andrade (2001), a decisão de irrigar pelo agricultor deve ser motivado por questões relacionadas à necessidade e possibilidade de irrigar. 
A decisão de irrigar ou não deve levar em consideração diversos fatores, entre os quais a quantidade e distribuição da chuva, o efeito da irrigação na produção das culturas, a necessidade de água das culturas e a qualidade e disponibilidade de água da fonte. $O$ fator mais importante que determina a necessidade de irrigação de uma certa cultura em uma região é a quantidade e distribuição das chuvas. Outras razões para se utilizar irrigação são o aumento da produtividade, a melhoria da qualidade do produto, a produção na entressafra, o uso mais intensivo da terra e a redução do risco do investimento feito na atividade agrícola.

Contudo, para que de fato a água utilizada na agricultura e pecuária possibilite o acesso ao alimento, este recurso deverá ter seus benefícios redistribuídos entre todos os agentes pertencentes às cadeias produtivas fruto da irrigação, do produtor rural ao consumidor final, evitando assim, conflitos de interesse e oportunismo no uso da água e possibilitando efetivamente alcançar um benefício social, ou seja, é necessária a definição do grau de prioridade na utilização da 'água para comer', associada e subsequente à 'água para beber', que é a água no seu valor intrínseco para manutenção dos ecossistemas, ou seja, como 'água para possibilidade de vida' (CHRISTOFIDIS, 2003).

Nesse sentido, a pesquisa evidencia as culturas exploradas e a expansão ou retração de área destinadas as mesmas, tendo como referência as cultivadas na 3o safra de 2015. Foi considerada a área destinada à produção das culturas do: alho, batata-inglesa, cebola, feijão, milho em grão, tomate e trigo no município de Cristalina, no período de 2006 à 2015, considerando a média obtida com base nos anos de 2006, 2007 e 2009 como valores de referência inicial e de 2013, 2014 e 2015 para definir os valores finais, objetivando delinear a configuração produtiva em Cristalina e os respectivos efeito-escala (expansão da área cultivada) e efeito substituição (uma cultura ocupar a área anteriormente cultivada por outra cultura) de cada cultura contemplada pelo estudo.

A análise do sistema, por meio do método shift-share, tem os resultados apresentados na tabela 4, a qual ilustra as culturas que sofreram mais alterações de suas áreas por efeito de substituição: feijão em grão, trigo e milho. Nesse sentido, feijão e trigo apresentaram os respectivos valores negativos: - 8.311,27ha, $-4.523,96 \mathrm{ha}$, enquanto tomate, cebola e milho obtiveram os valores positivos de $1.540,99 \mathrm{ha}, 1.278,12 \mathrm{ha}$ e 9.621,24ha. Quanto ao efeito escala, as culturas que mais se destacaram foram milho e feijão.

Tabela 4: Modelo referencial para otimização do uso do solo no município de Cristalina.

\begin{tabular}{|l|c|c|c|c|c|}
\hline \multicolumn{1}{|c|}{ Culturas } & Média inicial & Média final & Efeito área & Efeito escala & Efeito substituição \\
\hline Alho & $1.063,33$ & 1.700 & & 275,05 & 361,60 \\
\hline Batata-inglesa & $3.466,66$ & $4.396,66$ & & 896,74 & 33,25 \\
\hline Cebola & 600 & $2.033,33$ & & 155,20 & $1.278,12$ \\
\hline Feijão (em grão) & $16.666,67$ & $12.666,67$ & & $4.311,26$ & $-8.311,27$ \\
\hline Tomate & $2.056,66$ & $4.129,66$ & & 532,01 & $1.540,99$ \\
\hline Trigo (em grão) & $7.333,33$ & $4.706,33$ & & $1.896,95$ & $-4.523,96$ \\
\hline Milho & $7.925,33$ & $19.596,67$ & & $2.050,09$ & $9.621,24$ \\
\hline Área Total & 39.112 & $49.229,33$ & $10.117,33$ & $10.117,33$ & 0 \\
\hline
\end{tabular}

A análise gráfica foi utilizada para complementar a dos resultados do modelo shift-share, uma vez que este retrata apenas as condições iniciais e finais do sistema. Por sua vez, a análise gráfica permite observar a dinâmica de expansão e de substituição de culturas ao longo do período. Com o objetivo de melhor subsidiar a análise visual, uma vez que as diferenças de escala comprometem a visualização das oscilações, optou-se por agrupar as culturas de maior escala em uma figura (figura 5) e as culturas de menor 
escala em outro (figura 6). Como pode ser observado na Figura 5, há uma evidência de que a cultura do feijão foi substituída, inicialmente, por milho e trigo e este último foi, posteriormente, cedendo espaço para o milho.

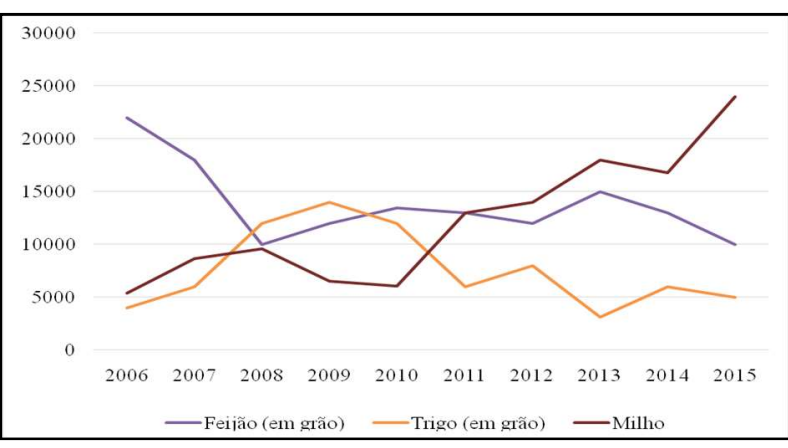

Figura 5: Representação da dinâmica de uso do solo com culturas de mais alteração em área.

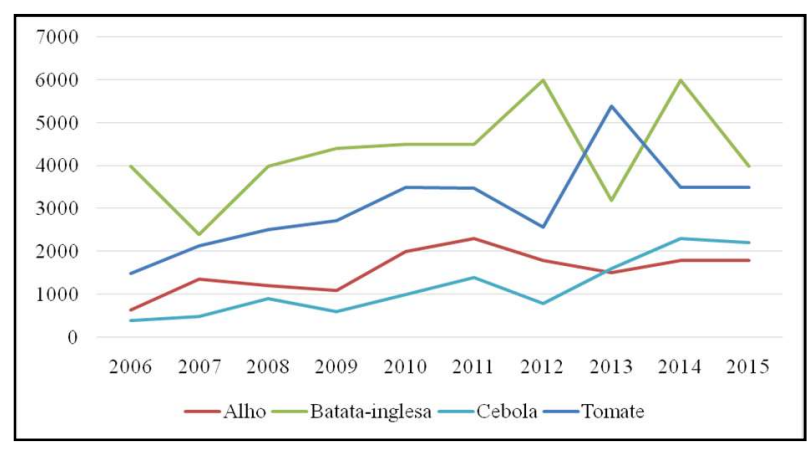

Figura 6: Representação da dinâmica de uso do solo com culturas de menor alteração em área.

Nesse sentido, a configuração da agricultura irrigada em Cristalina apresenta indicativos do que preconiza os modelos de expectativas racionais, idealizado por John Muth em 1960, afirmando que as expectativas dos agentes são formadas mediante probabilidade condicional, diante do conjunto de informações disponíveis no sistema econômico. Ou seja, informações sobre o modelo de previsão, sobre as políticas de governo e valores anteriores das variáveis importantes para a definição das expectativas, proporcionam experiências e uma base de dados, que possibilita aos agentes antecipar ou reagir de forma racional as ações e políticas futuras do governo no presente em conformidade com as expectativas formadas, minimizando a efetividade dessas políticas.

Desta forma, o uso de sistemas de irrigação proporciona ao produtor níveis de competitividade acima dos alcançados pelo modelo produtivo tradicional, especialmente pelo elevado índice de produtividade, até $40 \%$ superior em relação à produção de sequeiro, e pela possibilidade de redução de perdas decorrentes de fatores naturais. Tal fator se explicita, pelos dados apresentados de que nos últimos anos o incremento em 80\% na irrigação no município de Cristalina refere-se à expansão de área de produtores irrigantes, na construção de um arranjo produtivo que maximize o lucro.

O modelo de Muth foi um avanço aos métodos usados anteriormente de expectativas naive, adaptativas e de defasagens distribuídas. Instigado particularmente pelos ciclos observados nos produtos agrícolas e as ações adotadas pelos produtores, considerou-se que três fatores necessariamente influenciam a hipótese de que a distribuição de probabilidades das firmas tende a igualar à distribuição apresentada pela melhor teoria econômica existente para o agrupamento de informações acessíveis, sendo: as informações escassas; a estrutura do sistema econômico norteia a formação das expectativas; e uma projeção pública só afetará as operações do sistema econômico se forem baseadas em informações privilegiadas.

Assim, considerando oferta, demanda e equilíbrio de mercado de um produto em específico e suas variações de preço de curto prazo torna-se possível que agentes que estejam dentro do mercado e possuam informações privilegiadas lucrem com estes conhecimentos ao criarem mais que expectativas e sim oportunidades de mercado. 
Desta forma, as condições vantajosas na comercialização influenciam na definição das culturas a serem exploradas na 3 o safra, conforme preconiza a abordagem do modelo de expectativas racionais proposto por Muth, de que embasado em informações privilegiadas a oportunidade de lucro é ampliada pela diferença entre o preço efetivo em determinado período de tempo e o preço esperado conforme informações do passado. Trata-se, portanto, dos aspectos comportamentais que envolvem os atores econômicos, no sentido do risco moral que suas ações podem gerar na macroeconomia (CAMARGOS, 2004).

\section{CONCLUSÕES}

A promoção do desenvolvimento econômico local, deve ser definido como um processo sinérgico que envolva crescimento econômico e mudança estrutural, proporcionando melhoria na condição de vida da população local. Os resultados das análises apresentadas possibilitam inferir que há um conjunto de variáveis que explicam a dinâmica de culturas ao longo dos dez anos analisados. Por não ter sido possível obter uma relação estatística significativa entre as variáveis, sugere-se a avaliação de outros elementos de tomada de decisão de alocação do fator terra por parte do produtor, tais como: modelo de expectativas racionais, custos de transação, riscos dos fatores, dentre outros.

Todavia, os impactos socioeconômicos direto e indireto de regiões consolidadas como polo de irrigação vão desde o aumento da produtividade, produção regular e em escala, aumento na geração de emprego e por consequência lucratividade para o irrigante, sendo estas externalidades positivas, e como negativas, modificação do meio ambiente, salinização do solo, contaminação dos recursos hídricos, demandando portanto, a necessidade do uso da tecnologia de forma sustentável econômico, social e ambientalmente. Especialmente em Cristalina na microbacia do Rio São Marcos onde o conflito pelo uso da água entre irrigantes e a UHE Batalha se instituiu a partir do Marco Regulatório da Resolução no 562/2010, além de potencial conflito intrassetorial, a gestão dos recursos naturais torna-se aspectos condicionante para a promoção do desenvolvimento local.

\section{REFERÊNCIAS}

ACKOFF, R. L.. The future of operational research is past. The Journal of the Operational Research Society, v.30, n.2, p.93104, 1979.

ANA. Agência Nacional de Águas. Plano de recursos hídricos e do enquadramento dos corpos hídricos superficiais da bacia hidrográfica do Rio Paranaíba. Brasília: ANA, $2013 a$.

ANA. Agência Nacional de Águas. Subsídios para a discussão da compatibilização da geração de energia hidrelétrica com expansão da agricultura irrigada na bacia do Rio São Marcos. Brasília: ANA, 2013b.

ANDRADE, C. L. T.. Seleção do sistema de irrigação. Sete Lagoas: Embrapa, 2001.

ARENALES, M.. Pesquisa operacional. Rio de Janeiro: Elsevier, 2011.
BORGES JÚNIOR, J. C. F.. Computational modeling for irrigated agriculture planning. Part I: general descriptionand linear programming. Revista Brasileira de Engenharia Agrícola e Ambiental, Campina Grande, v.12, n.1, p.3-11, 2008.

CAMARGOS, L. R.. Fundamentos para uma teoria de expectativa econômica. São Paulo: 2004.

CARNEIRO, G. C.; DINIZ, N.; MENEZES, P. H.. Aplicação de um sistema de informação geográfico como instrumento de gerenciamento de dados dos recursos hídricos superficiais de irrigação pelo sistema de pivô central do município de Cristalina-GO. In: SIMPÓSIO BRASILEIRO DE SENSORIAMENTO REMOTO, 15. Anais. Curitiba: INPE, 2011.

CHRISTOFIDIS, D.. Água, ética, segurança alimentar e sustentabilidade ambiental. Bahia Análise \& Dados, Salvador, v.13, p.371-382, 2003. 
GOMES, M. F. M.. Efeitos da expansão da produção de soja em duas regiões do Brasil. Revista de Economia e Sociologia Rural, Brasília, v.29, n.3, p.209-227, 1998.

IBGE. Instituto Brasileiro de Geografia e Estatística. Goiás. Cristalina: IBGE, 2016.

IBGE. Instituto Brasileiro de Geografia e Estatística. SIDRA: Sistema IBGE de Recuperação Automática. Rio de Janeiro: IBGE, 2014

IBGE. Instituto Brasileiro de Geografia e Estatística. Tabelas completas. Rio de Janeiro, 2013.

PIMENTEL, C. R.. Evolução recente e tendências da fruticultura nordestina. Revista Econômica do Nordeste, Fortaleza, v.29, n.1, p.11-19, 1998.

SANTOS, M. A. L.. Model of lineal programming for economical optimization of the district of irrigation Baixo Acaraú-CE. Caatinga, Mossoró, v.22, n.1, p.6-19, 2009.
SILVA, L. L.. O papel do Estado no processo de ocupação das áreas de Cerrado entre as décadas de 60 e 80 . Caminhos de Geografia, v.2, n.2, 2001.

SIMÕES, R. F.. Métodos de análise regional e urbana: diagnóstico aplicado ao planejamento. Belo Horizonte: UFMG, 2005

UNESCO. Organização das ações Unidas para a Educação, a Ciência e a Cultura. Educação para um futuro sustentável: uma visão transdisciplinar para ações compartilhadas. Brasília: UNESCO, 1999.

VEIGA, J. E.. Desenvolvimento sustentável: o desafio do século XXI. Rio de Janeiro: Garamond, 2005.

YOKOYAMA, L. P.; IGREJA, A. C. M.; NEVES, E. M.. Modelo 'Shift-Share': uma readaptação metodológica e uma aplicação para o Estado de Goiás. In: CONGRESSO BRASILEIRO DE ECONOMIA E SOCIOLOGIA RURAL, 27. Anais. Piracicaba: 1989. 